\title{
The Research on Payment of the Cost of Medical Insurance and Its Development in China
}

\author{
Yating Dong ${ }^{1} \& \mathrm{Lu} \mathrm{Jin}^{2}$ \\ ${ }^{1}$ School of Management, Shanghai University of Engineering Science, Shanghai, China \\ ${ }^{2}$ School of Social Science, Shanghai University of Engineering Science, Shanghai, China \\ Correspondence: Yating Dong, School of Management, Shanghai University of Engineering Science, Shanghai, ON., \\ Long Teng Road No.333, China. Tel: 86-188-1823-3656. E-mail: 250844110@qq.com
}

Received: April 23, $2014 \quad$ Accepted: May 5, $2014 \quad$ Online Published: June 4, 2014

doi:10.5430/sass.v1n2p64 URL: http://dx.doi.org/10.5430/sass.v1n2p64

This work was supported by Shanghai Science and Technology Commission of scientific research and innovation projects. (No. 13KY0341).

\begin{abstract}
At present, along with the reform of China's medical insurance system, the mode of payment of costs is evolving. This article introduced the general situation of payment mechanism in urban employee basic medical insurance, basic medical insurance system for urban residents and new rural cooperative medical insurance payment mechanism. It took Jiangsu province as example, separately described the revaluation of 3 medical insurance payment, analysis its result. Finally on this basis, putting forward the ideas for the future of insurance system and its method of payment.
\end{abstract}

Keywords: Medical Insurance, Mode of Payment, Reformation

\begin{abstract}
"Medical treatment is difficult and expensive" issue currently is still a hot and difficult problem attracted widely social concern, which also plagued government and health administrative departments. On the early April of 2009, CPC Central Committee and the State Council issued "Opinions on deepening the reform of the medical and health." It proposed the short-term goal which was "effectively reduce the burden of medical costs residents, alleviate the 'medical treatment which is regarded as difficult and expensive,"' and the long-term goal was refer to establish and improve the basic medical and health system covering urban and rural residents, to provide people the safe, effective, convenient and affordable health care services. To achieve the goal of health care reform, and make it better to implement the party and the government benefiting policy, we must further deepen and innovate the reform of medical insurance system. And take reasonable and good use of limited medical insurance fund which contribute to not only maximize Medicare functions, but also to promote the healthy development of the hospital, building a harmonious doctor, suffering, paul tripartite relationship.Medical payment methods as doctors, patients, insurance payment mechanism and regulating lever between the three parties, it is related to the tripartite balance of interests and a stable of medical insurance system. To ensure the sustainable development of the medical insurance system, we must summarize past experience on the basis of payment, and further improve the medical insurance payment.
\end{abstract}

\section{Survey of Medical Insurance Payment Mechanism in China}

Reform of Medical security system in China fit in with China's economic system reform, the reform has been taken for more than 60 years, there has been a fundamental change in the system which is the changed the free medical care before the reform into the social medical insurance after reform. At present, it formated the basic medical security system with Chinese characteristics. (see Figure 1) 


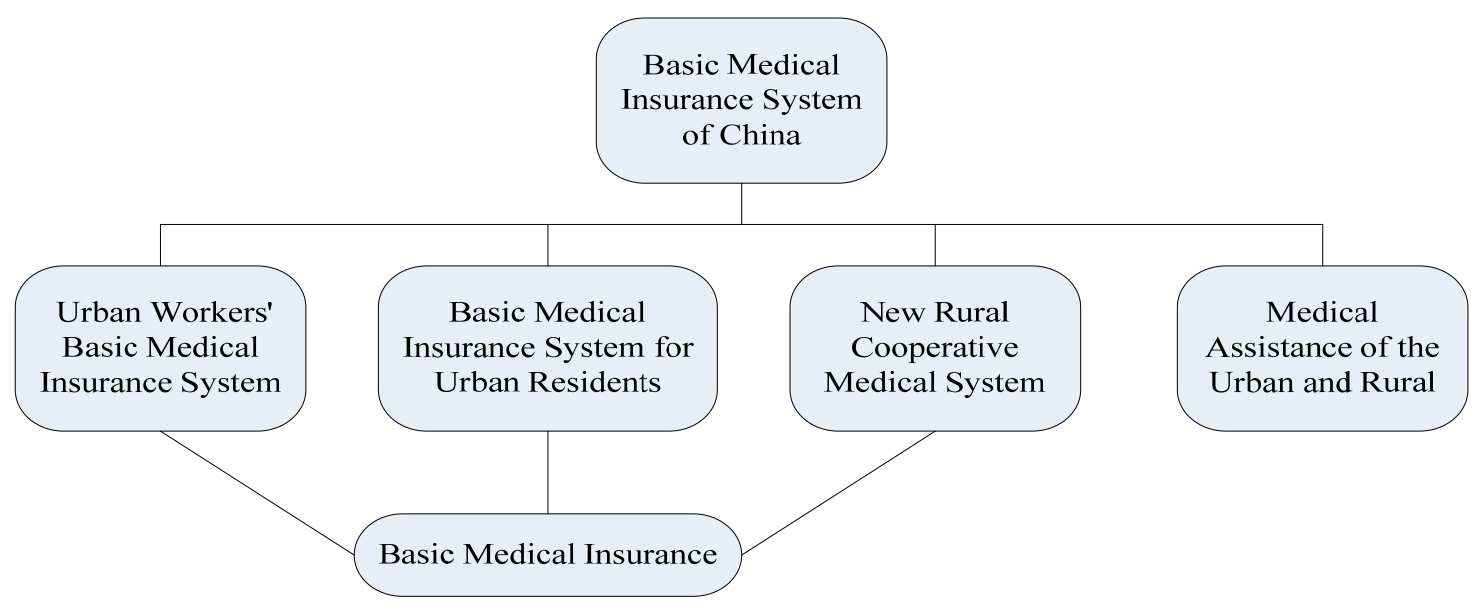

Figure 1. Basic Medical Insurance System of China

\subsection{An Overview of Medical Insurance Payment Mechanism}

Current basic medical insurance system is composed of the urban workers' basic medical insurance system, basic medical insurance system for urban residents, and new rural cooperative medical system, and its population covering urban employment, urban and rural non - employed population, to achieve the goal of full coverage of medical insurance. By July 2010, the basic medical insurance had covered 1.25 billion people.

The three main elements of the basic medical insurance system in China as shown in table 1.

Table 1. Current basic medical insurance system in China

\begin{tabular}{|c|c|c|c|}
\hline & $\begin{array}{l}\text { the basic medical insurance } \\
\text { system for urban employees }\end{array}$ & $\begin{array}{l}\text { basic medical insurance system } \\
\text { for non-working urban } \\
\text { residents }\end{array}$ & $\begin{array}{l}\text { new type of rural } \\
\text { cooperative medical care } \\
\text { system; }\end{array}$ \\
\hline $\begin{array}{l}\text { Legal } \\
\text { foundation }\end{array}$ & $\begin{array}{l}\text { For the establishment of the } \\
\text { provisions of the basic medical } \\
\text { insurance system for urban } \\
\text { workers } 1998\end{array}$ & $\begin{array}{l}\text { The State Department guidance } \\
\text { on carrying out pilot of basic } \\
\text { medical insurance for urban } \\
\text { residents } 2007\end{array}$ & $\begin{array}{l}\text { Decision on establishing } \\
\text { new rural cooperative } \\
\text { medical system } \\
2003 \\
\end{array}$ \\
\hline Coverage & urban employees & $\begin{array}{l}\text { urban residents without } \\
\text { employee's insurance }\end{array}$ & rural population \\
\hline Model & $\begin{array}{l}\text { social unified fund + personal } \\
\text { accounts of the Fund }\end{array}$ & social unified fund & $\begin{array}{l}\text { social unified fund, part of } \\
\text { areas have family account }\end{array}$ \\
\hline Fund raising & $\begin{array}{l}\text { Enterprise : } 6 \text { ( } 70 \% \text { in social } \\
\text { accounts, } 30 \% \text { in individual } \\
\text { accounts ), Individual : } 2 \% \text { ( all } \\
\text { included in the personal } \\
\text { account ) }\end{array}$ & $\begin{array}{l}\text { Individual + government } \\
\text { subsidies }\end{array}$ & $\begin{array}{l}\text { Individual + government } \\
\text { subsidies }\end{array}$ \\
\hline \multirow[t]{2}{*}{ payment } & $\begin{array}{l}\text { Social Fund : outpatient } \\
\text { hospital + chronic diseases } \\
\text { personal accounts : the clinic } \\
\text { ( could cover hospital pays } \\
\text { part ) }\end{array}$ & $\begin{array}{l}\text { Inpatient + outpatient ( ill } \\
\text { medical expenses ) ( parts ) }\end{array}$ & $\begin{array}{l}\text { Inpatient }+ \text { outpatient } \\
\text { ( parts ) }\end{array}$ \\
\hline & $\begin{array}{l}\text { Set minimum paid and highest } \\
\text { paid line ,for about } 85 \%\end{array}$ & $\begin{array}{l}\text { Set minimum paid and highest } \\
\text { paid line ,for about } 60 \%\end{array}$ & $\begin{array}{l}\text { Set minimum paid and } \\
\text { highest paid line, for } \\
\text { about } 50 \%\end{array}$ \\
\hline $\begin{array}{l}\text { Management } \\
\text { Level }\end{array}$ & $\begin{array}{l}\text { social pooling at } \\
\text { municipal-level }\end{array}$ & $\begin{array}{l}\text { social pooling at } \\
\text { municipal-level }\end{array}$ & $\begin{array}{l}\text { Social pooling at } \\
\text { district-level }\end{array}$ \\
\hline $\begin{array}{l}\text { competent } \\
\text { authority }\end{array}$ & $\begin{array}{l}\text { Human resources and the } \\
\text { Department of Labor and Social } \\
\text { Security }\end{array}$ & $\begin{array}{l}\text { Human resources and the } \\
\text { Department of Labor and } \\
\text { Social Security }\end{array}$ & Health Department \\
\hline
\end{tabular}




\subsection{Mechanism of Three Major Medical Insurance System in China}

Urban Employee medical insurance payment structure with a "plate - type" of the chart to be described (as shown in figure 2). Personal Account to pay for the clinic and the small medical expenses and manpower, social funds used to pay the hospital and large medical expenses. Social fund set up the pay lines as lowest and highest which calculated as Local average annual wage of $10 \%$ and $400 \%$ respectively. The personal pay part in the hospitalization medical expenses, which ranges from lowest to highest line, the pay scale will be determined by local governments. The above part could be solved by the supplement medical insurance such as enterprise supplementary insurance, business insurance.

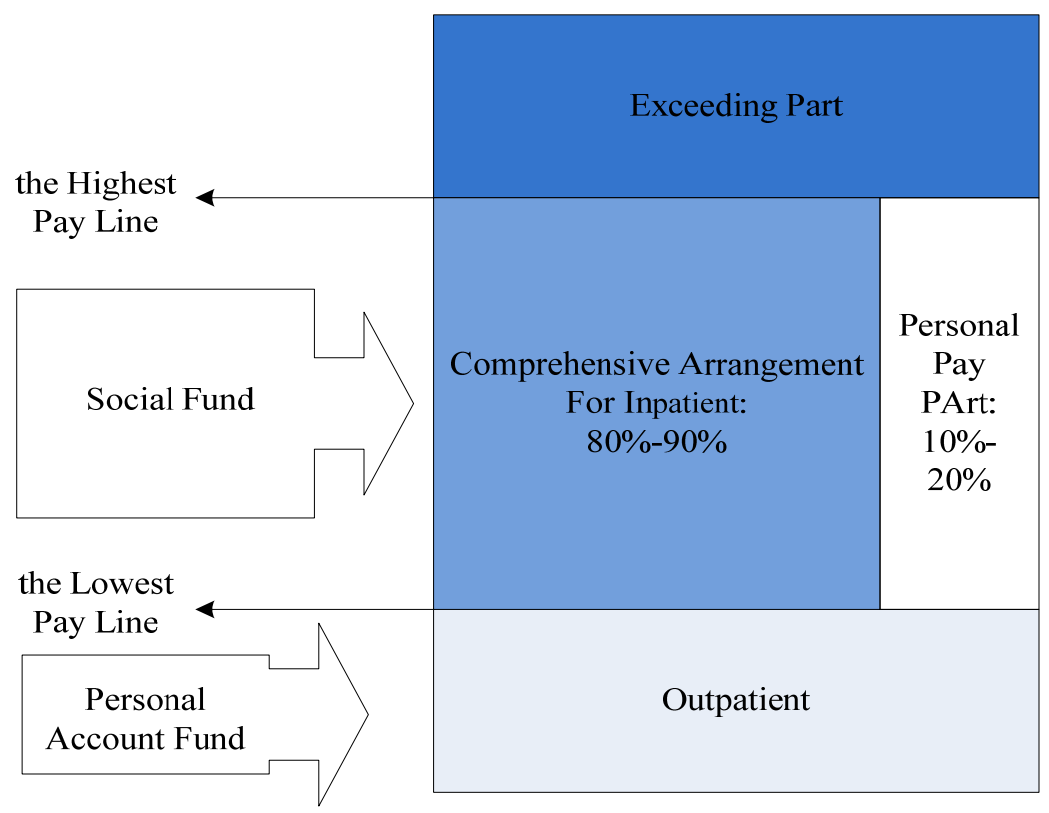

Figure 2. Health insurance cost - sharing structure

Basic medical insurance system for urban residents is mainly for the "Comprehensive Arrangement for serious disease", and its fund is used for the participated residents' inpatient and outpatient health expenses, if the condition is tended to be allowed, the outpatient expenses could be accounted into social fund gradually.

The new type of rural cooperative medical care system mainly concluded 3 modes as: comprehensive arrangement for serious disease, comprehensive arrangement for serious disease plus out-patient plus hospital outpatient family account, and outpatient co-ordinate. Comprehensive Arrangement for serious disease refers to the only comprehensive arrangement for serious disease fund to the hospital and some special kinds of diseases make up a large outpatient costs. The Comprehensive arrangement puls family account refers to establish a comprehensive arrangement for serious disease fund to the hospital and some special kinds of diseases make up a large outpatient costs, outpatient family account fund established to compensate outpatient costs. Comprehensive Arrangement puls outpatient social fund refers to through the establishment of co - ordination funds make up for inpatient and outpatient costs, respectively.Different Experimental areas should be based on social, economic and human situation on the ground, select the appropriate mode of compensation to local conditions.But the overall trend of development of new rural cooperative medical system should be gradually fading family account,transiting to comprehensive arrangement for serious disease or in-patient and out-patient integrated primary mode of compensation, enhanced cooperative medical system's ability to resist risks.

\subsection{General Situation of Medical Insurance Premium Payment in China}

China's currently basic medical insurance payment method could be basically divided into two categories, which is prepaid and post pay system. Within these two categories, there are five different form of payment. 
1) Prepaid

Prepaid system generally refers to in the medical costs before they occur, the insurer shall according to certain standards of medical expenses paid in advance to medical institutions. Criteria for payment within a certain period of time is fixed, for a period of change of the actual situation and then adjust accordingly. Prepaid prepaid system is mainly composed of the total principal paid, the head paid and grouped by disease - related payments.

Global Budget refers to the total budget based on the the service condition of health care providers considered by government or insurance institution, in accordance with certain criterion, for example number of institutions, technologies, services, people and amount of hospital services (including outpatient visits, hospital visits and costs, and so on), to decide the periodical budget aggregates of medical institution, as the maximum of the payment for medical insurance institution. Once you have determined the total amount cannot be changed any more.

Capitation refer to the integrated insurance institution combined with both insurance and medical care, it will ba based on the arranged number of hospital or medical service object and each of the fees shall be paid under the quota, reimbursement of medical expenses is in advance, so as to encourage them take the fee controlling measure consciously, such as disease prevention, health education, regular physical activity, with a view to minimizing the incidence and reduce expenses.

Diseases Related to Groups, DRGs. From in the 1970 of the 20th century, the United States on disease diagnosis related groups (DRGs) conducted research, and established the diagnosis - related groups. That is, according to the international classification of diseases, diagnosis of patients to be divided into several DRGs, for each DRGs specified price, respectively, in the whole process of diagnosis and treatment of patients with disposable to pay the hospital costs of the specified price. The principle is to make the very complex and random medical payment process into standardization, diagnosis and treatment of the patient will be handled as a whole system, the hospital has nothing to do with the actual cost of revenue, and relating to each case and its diagnosis. DRGs is the ideal case mix mode in the current world, its integrated reflects the severity of the disease, the prognosis, treatment level of difficulty, strength and resource consumption of medical services. This is a relatively reasonable approach to medical management and Medical Quality Evaluation Method for Relative objective. In addition to the United States, Australia, Germany and Argentina and other countries also use this as a primary means of payment of medical expenses.

2) Post pay system

Post pay system generally refers to after the cost of health insurance be taken into place, the insured person should pay the expenses to medical institution based on the actual condition. This is the payment system has long been used in China. The post pay system mainly concluded Fee For Service and Service Unit, etc.

Fee For Service, FFS refers to design each service item in the process of medical service price, according to the number of medical institutions to provide services and forms of payment for medical services. This is our country has been adopted, and is also one of the most widely used method of settlement of medical expenses. Services fee of the project is to identify the original cost basis, also is the foundation of project cost accounting, and charged according to the standard - setting and adjustment.

Service Unit, also called the average scale of fees paid, is a form of payment between paid by project and by disease. The average standard of payment are by sampling a certain percentage of outpatient prescriptions and hospital medical records, meanwhile after deducting reasonable medical expenses which not counted every time, it took patients in the hospital into a daily or other unit to pay.

But in practical use, it often based on real situations on the creative use of the various methods of payment.

\section{Reform of Medical Insurance Payment Methods and Its Effectiveness in China -- Taking Jiangsu Province as an Eexample}

2.1 Basic Medical Insurance of Employees

1) Huaian-Disease score settlement approach

Disease score settlement means according to the different required for different diseases relationship between ratio of medical expense, for each disease determine the appropriate values, composing the hospital to hospital and discharged every disease passengers, Calculate the total value to make fee payment clearing.

Effectiveness analysis: The payment reform of HuaiAn strengthened the fund management, also establish a 
self-regulatory mechanism, which prompted the hospital to reverse the handling agency from passive to positive, achieved the remarkable result. Original method taken by project pay or by way of real settlement, resulting in rising per capita medical, health insurance and Manpower fund deficit that year. During the period of fully Implemented in 2004 "disease score Settlement Scheme" implemented in those days, hospitalization fee is $\$ 6692.3$ per capita, hospital days per-time is 26.16 days, respectively over the previous year fell by $22.58,20.68,27$ per cent paid for, and was flat in 2003. This lind of Score settling in hospital fees based on the sickness inflated to be effective in containing, health insurance fund expenditure pressure decreases, the per capita cost and time are in the hospital days have shown a downward trend.

2) Zhengjiang - Total budget, elastic settlement, part of the disease based payment

Zhenjiang as one of the two felled the first batch of pilot cities across the country, from the medical project launched in 1994 to present, on payment methods is going through continuous exploration and improvement

In 1995-1996, a single "flat rate payment system" approach got effective controlling result, but in 1996, after people come to be familiar with the payment methods in medical institutions, decomposition of non - standard workload behavior occurs, resulting in serious rebound.

In 1997, to explore "The flat rate payment system under the total control" approach, obvious effect had been shown on the health insurance fund balance, medical controlling had been taken from a macro level. But also happened to a certain extent, bruised part of the health care quality, patient enthusiasm of many medical institutions

1998 "Global budget and final accounts of the flat rate payment system, budget allocation, flexible, assessment incentives" made monthly fluctuation of medical expenses to be easing, cost control have also improved for the former pine tight after, but the decomposition of prescriptions are still there, doctor - patient contradiction is also more prominent.

In 1999-2000, to explore the implementation of "personal accounts in real pay, and Manpower total control" approach, Ideal effect had been obtained in 1999, In 2000 patients induced by medical institutions use the personal account behavior occurs, so that some patients into overall settlement, raising the overall pressure on the Fund.

Beginning in 2001, "the total budget, flexible combination of pay settlement, part of the disease by disease" integrated billing method, both total control, or pay a single disease. Its biggest advantage is that arouse the enthusiasm of the hospital, control costs, the hospital and healthcare sector joint management of the Health Insurance Fund. This method of paying for outpatient fee depending on the different levels of medical institutions and points of outpatient cost: (1) for community health service institutions to adopt emergency medical expenses "Patients head" at the core of the "total budget management" method of settlement; For more than two levels and designated hospitals, emergency medical expenses to implement "accounts of the total budget, elastic" method of payment. (2) For inpatient costs to implement "by service units pay" payment methods, secondary and above designated hospitals implemented partial hospitalization costs based on the situation of the disease.

In this payment method "When year-end clearing flexible settlement" is a bright spot,all estimated gross index was not completed by the actual settlement, and $40 \%$ of the balance of costs for the award.

Zhenjiang method of payment, during the implementation of 8 years, the cost of an average annual growth of 9-12, funds increase of 10-14 over the same period, costs less than the increase in the Fund. Implementation of the health care payment reform with concrete, realistic changes, and continuously explore the medical, patient, and the tripartite combination of interests, and strive to achieve balance the interests of all parties. Of these, in 2004, adjusted to your payment method, introduced by the Head of Clinic Visits pay for hospitalization. In 2008 the introduction of the social medical insurance in Zhenjiang medical expenses settlement procedures, adjusting Medicare payments to the community.

\subsection{Basic Medical Security for Urban Residents}

1) Nanjing - Certain kind of diseases take norm settlement, hospitalization expense implement the control indicators settlement

In 2007, in Nanjing under the Nanjing Provisional Measures on basic medical insurance system for urban residents and the basic medical insurance system for urban residents in Nanjing, the provisional rules for the implementation of the measures in place appropriate administrative measures for the settlement. Outpatient more than afford to pay the standard and capped line ( $\$ 600$ ) between the part of the medical expenses payable by the fund in real settlement; Outpatient serious illness medical expenses by the Fund in real settlement, certain kind of medical expenses by norm settlement ( after hemodialysis, peritoneal dialysis and kidney transplantation 3 anti - rejection therapy outpatient 
illness, its norm is $\$ 48,000$ per person per year in 2007 ); Inpatient costs are based on settlement control indexes of settlement. Average monthly indicators of hospital admission fees lower than in the hospital and settlement control, in real disbursed; Equal to or higher than the hospital billing control index, according to the residential settlement control index. Finally, through year-end accounts, determining the monthly settlement reserve fund should be $5 \%$ of the settlement amount disbursed. This mixed method of payment in Nanjing was to encourage the reasonable control of hospitalization medical cost increases in medical institutions

\section{2) Lianyun Gang-Total Quantity Control}

According to the regulation om august 2007, The interim settlement for the cost of basic medical insurance in Lianyun Gang., total control medical costs had been implemented, that is, according to raise the total amount of funds of basic medical insurance for urban residents that year, after extracting certain proportion of risk adjustment payments, and the rest part would be charged as the year total expenditure budget for basic medical insurance of medical expenses, with fully assigning and controlling . Initial fixed - point medical institutions of the total amount of medical expenses in the Budget indicator, in real settlement balances carried forward to the next year using indicators to the hospital; Unreasonable growth of indicators exceed the total budget section shall not be paid; Reasonable growth in part, determined by audit of medical insurance agencies upon judicial review of labour and finance ministries, to give appropriate subsidies from the regulation of the extraction of gold. In addition, the medical insurance agencies in determining the total Budget Index 90\%, the first of the monthly prepaid fixed - point medical institutions, the remaining $10 \%$ end of year of assessment there shall be cashed with no violation; Any offenders should be clawing back illegal funds in accordance with the relevant provisions for punishment.

Lianyun Gang, after its extraction of risk funds, regulation fund total control of your payment method,for one hand it makes it possible to control the use of the health insurance fund, prevent the the risk of funds running; For the other hand, to check the fixed - point medical institutions, establish the appropriate punishment measures to promote the reasonable control of the medical expenses of medical institutions.

\subsection{New Type of Rural Cooperative Medical Care System}

1) Suzhou, Wujiang - The hospital cost settled by the disease

Officially launched in Wujiang city in May 2008, the inpatient expense started to be settled by disease. As of April 2010, a total 5,570 cases of disease cases of settlement have been carried out in the hospital, Fund Expenditure of $\$ 14.8981$ million, including 4,899 cases of the local hospital, $88 \%$ of the number of cases, township $671,12 \%$ of the number of cases.

The main ideas: First, select the kind of disease, developing programme. In accordance with the standards of the International Classification of Diseases (ICD-10), 60 species of identified in the pilot plant in Suzhou, selected 10 diseases as one of the first pilot disease.In 2008, expanded the pilot disease to 17. In addition, compensation ratio in patients with diseases of the pilot was set: A hospital insurance fund and the individual payment ratio of 7:3 for First-Level hospitals; 6:4 Second-Level hospitals, to guide the patients go the grass-level hospital for treatment. The actual medical expenses is below to the disease clearing fee, according to the actual proportion of individuals sharing payment of medical expenses and provisions, and the rest settled by the insurance agencies and hospitals; If the actual medical expenses above by disease settlement cost, beyond the part is borne by the medical institution. The second is a synchronous implementation for major disease relief. When the insured children suffering from cancer, leukaemia and other serious illness or medical cost more than $\$ 50,000$ for the year, its compensation to be paid after Section $80 \%$ of aid; When getting involved farmers suffering from uremia, cancer and other major diseases, its compensation as $95 \%$ highest would be paid after the payment of the demanded party. In 2009, 13,739 people had enjoyed major disease medical aid, reduced total cost of \$22.7147 million. Third, Credit Card Clearing Houses, with reported in real time. Third, Credit Card Clearing Houses, with reported in real time. For the convenience of insured persons, streamline processes, increase efficiency, established and improved a new rural information network, did it in real time with reported, monitored in a timely manner.

Analysis of the effectiveness : first, implemented by disease settlement can lighten the peasants' burden of medical expenses, hospital medical savings achieved an average of 21.95, First_Level hospital for 23.5\% First_Level hospital for $21.9 \%$. Second, as the highest order against related diseases, exceeding part, was be borne by the medical institution, which forced a greater focus on cost accounting of medical institutions to improve efficiency. Third, by disease settlement to maximize the opportunity to put an end to the doctor with medical personal vendetta, doctors have to start with improving the level of health care, reduce medical costs, coupled with the disease settlement price codes, patients' right to be fully reflected and assurance. Fourth, settled by disease, it was cheap, standard fixed, clear 
the powers and responsibilities, monitoring information timely to the protection of the safe operation of the Fund plays a larger role.

Suzhou, as the early reformed city in Jiangsu Province, its New Rural Hospital was formally launched in 2006 by disease settlement pilot, The first batch of pilot involving a total of 37 diseases, "the two cities Area" (Zhangjiagang City, and Changshu and Wuzhong District ). Pilot extended to rural areas in the city in 2008, increased disease to 60 in 2009. According to statistics, at the end of may 2010, the actual number of species of developing disease as 25 , clearing 25,260 cases of discharge passengers. According to surveys, implementation of disease after the settlement, the cost of an average decline of 17.6 per cent, average discharge reduction in the cost of 892 yuan. Duding these 3 years, the city's health care costs had been reduced as a total of nearly 220 million yuan. Its health care costs controlling, achieved good results. Among them, the disease by disease settlement price formation by the handling agency on behalf of the insured person, in the professional On the basis of the Information Disclosure of peer, baseline data, In the Professional Information on the basis of reciprocity, disclosure of baseline data, negotiate with service providers, patients' rights are protected and reflect.

2) Jiangyin city of Wuxi-DRGs

Approach: first, the scientific measurement of single disease rates with more than 20 field research, collected and arranged many parts of the disease cost data for the calendar year, After 5 rounds of actuarial and eventually selected up to 10 fewer complications of diseases, clinical path clear for single disease quota payment, Fixed the highest standards for the 3 years before the disease hospitalization costs an average of $90 \%$. Single disease established a fixed price for the standard treatment in second-level medical institutions, the need to pay fees to fund compensation cost - sharing ratio is 5:5; The ratio of medical institutions at the level of 4:6. If the actual medical expenses below to the fixed price, proportion to be paid in accordance with the regulations; Involved actual expenses higher than the fixed price portion of medical expenses borne by the fixed - point medical institutions. Second, strengthening supervision, and gradually improving. Individual differences due to the particularities of the medical profession and disease, and implementation of single disease toll is bound to cause active avoidance of medical institutions. To this end, Jiangyin adopted a series of regulatory measures: A hospitalization check on the patient describes policy. In hospital identification in a timely manner, to comply with the introduction of single disease hospital settlement policy and profits. Second, phone calls, followed. On a return visit by a single disease patients pay, understand the costs and the presence of non - standard medical practice. Third is the usage of economic levers, increasing the intensity of violations punishment. In addition, fixed payment of medical institutions fees with single disease will be included in the annual assessment, examination results be linked to the disbursement of funds.

Analysis of the effect: From the exploit in 2007 on single diseases since the quota payment started, new rural single disease, Jiangyin, Wuxi fixed number of paid a total of 1484 knots, compensation totaling $\$ 17.1292$ million, the actual compensation for 45.7 per cent, 10 fixed pay a single disease disease average cost of $\$ 2453.6$, Fell by 30 over the same period. Practice has shown that single disease quota payment to pay standards for some hospital services provided, Reduction of getting involved in the actual spending in the economy and strengthen quality management of disease, guarantee the safety of health care.

\section{Conception of the Future of Medical Insurance System and its Method of Payment}

Under the social security "twelve-five" plan of the platform for direction, The State made it clear in "twelve-five" period, institutional co-ordination and convergence, pension, health insurance continuation to put forward specific requirements, make the next five years to accelerate the construction of the social security system covering both urban and rural residents. Meanwhile, the institutional reform of the State Council circular of the publication in march and the functional transformation programme, Article 17th of which made "The integration of urban employee basic medical insurance, basic medical insurance system for urban residents and responsibilities of the new rural cooperative medical system". And it should be completed before the deadline at the end of June 2013.This means that, for a long time in the "Fragmentation" of the state medical insurance system will be conducted on content improvement, on the structure of consolidation in the level of closing the gap, and shaped by the pilot. With the integration and normalization of medical insurance system, reform of medical insurance premium payment will be carried out.

Medical insurance system integration and improvement requires not only system integration, but also institutional integration. On the one hand, the three systems including urban workers' basic medical insurance, urban residents' basic medical insurance and new rural cooperative medical system, have been gradually integrated into a unified, 
four-level medical insurance system. On the other hand, it requires institutional reform and function transformation. From a practical point of view, multiple sector management is inappropriate. Instead, it is achievable for a unified medical insurance system to manage by one department called Ministry of Human Resources and Social Security of the People's Republic of China (Referred to as MORHSS).

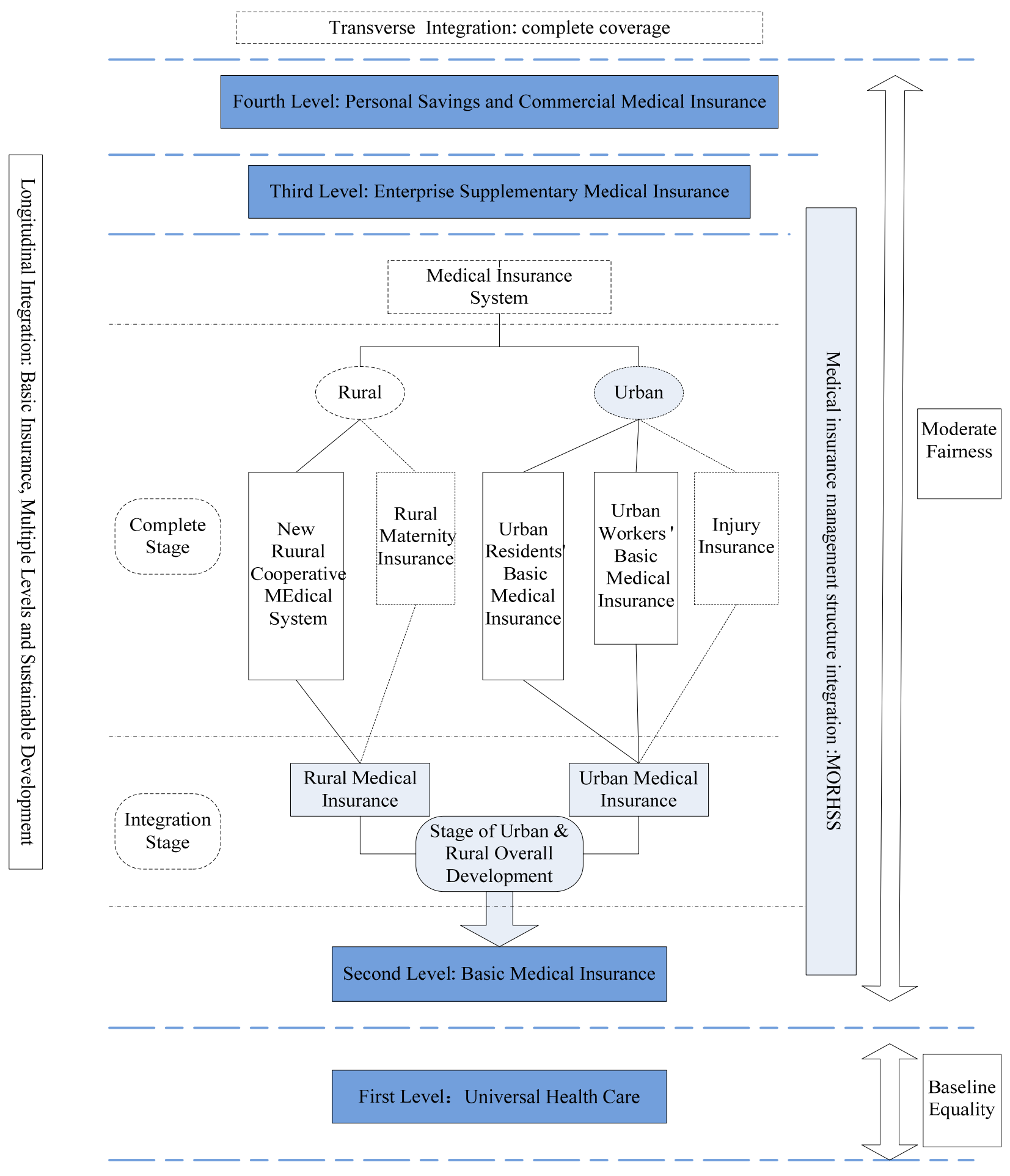

Figure 3. Frame on integration and improvement of China's medical insurance system 
In the framework of this system, medical insurance system is divided into four different protection levels: Universal Health Care, Basic Medical Insurance, Enterprise Supplementary Medical Insurance and Personal Savings and Commercial Medical Insurance.

In Universal Health Care and Basic Medical Insurance, the security object is to all citizens.Financing funded by government, society and residents. They are established based on government, supplemented by the residents, community funding for compensation, aim to build a universal health care system.

The security object of Enterprise Supplementary Medical Insurance covers two parties of all have employment relationship,including employers and their employees, allowing urban and rural residents as freelancers to participate in the insurance by individual payment. Financing funded by employers and their employees according to the proportion. As long as the employee insured, he can benefit, even for temporary workers. The major diseases and general outpatient treatment is its security target.

Personal Savings and Commercial Medical Insurance are mainly financed by individuals. It is to obtain protection by purchasing commercial insurance and transferring income among family members.

One element in such a universal coverage under the National Health Insurance system, the cost of medical insurance payments will reform, that is, outpatient medical services, third party implementation of heads of medical institutions pay the costs of the primary method of payment; Hospital medical service model, the implementation of the total amount of payment, pay and other integrated mode of payment as diseases, develop uniform standards of treatment of disease treatment and fees. First Establishment of a community and basic health services; serious disease hospital referral system.

\section{References}

Chu, T. Y. (2012). Study on the development of medical insurance system in China - in the perspective of international comparison. Northeast University of Finance: finance.

Dong, Z. Y. (2010). Deepening the reform of medical insurance premium payment, review and suggestions to perfect medical insurance premium payment. China Medical guide, 26, 166-168.

Hu, Y., \& Leng, M. X. (2011). Three basic medical insurance reform in Jiangsu Province and exploration. Hospital management in China, 02, 48-51.

Li, S. Z. (2008). Comparative Study on medical payment methods at home and abroad. Chongqing medicine, 09, 993-995.

Sun, J., \& Guo, Q. (2005). Comparison and Enlightenment of payment of medical expenses. The People's Liberation Army Hospital Management Journal, 12, 471-472.

Wang, X. J., \& Zhu, S. J. (2006). Comparison of methods of payment of medical expenses. Hospital management, 07, 481-483.

Wu, G. G. (2011). Comparison of methods of payment of medical expenses of the world. China's health, 11, 31-32.

Xiong, X. X., \& Xian. J. (2012). Study on Urban residents' basic medical insurance payments for outpatient and manpower policies. China's medical insurance, 10, 34-37.

Xu, C. Y., \& Caroline Peng. (2008). Comparative analysis of methods of payment of medical expenses. China Medical Record, 11, 17-18.

Xu, H. H. (2011). Urban Employee basic medical insurance fund. China Mining University: School of Management.

Zhang, Y. Y. (2007). Shanghai medical insurance fund research on monitoring. East China Normal University: College of Public Administration. 